\title{
Automatic Floor Cleaning Robot Using Arduino and Ultrasonic Sensor
}

\author{
Yuda Irawan ${ }^{1}$, Muhardi ${ }^{2}$, Rian Ordila ${ }^{3}$, Roni Diandra ${ }^{4}$ \\ 1, 2,3 Department of Information System, STMIK Hang Tuah Pekanbaru, Pekanbaru, Indonesia \\ Email: ${ }^{1}$ yudairawan89@gmail.com, ${ }^{2}$ muhardi.yudie@gmail.com, ${ }^{3}$ rian.68x@gmail.com, ${ }^{4}$ ronidiandra@gmail.com
}

\begin{abstract}
The entire floor cleaning robot is divided into several parts, namely consisting of an Ultrasonic Sensor, Motor Shield L298, Arduino Uno microcontroller, Servo, and Dc Motor. This tool works when the Arduino Uno microcontroller processes the ultrasonic sensor as a distance detector and a DC motor as a robot driver, then the DC motor is driven by the Motor Shield L298. When an ultrasonic sensor detects a barrier in front of it, the robot will automatically look for a direction that is not a barrier to the floor cleaning robot. The distance value on the sensor has been determined, that is, when the distance read by the ultrasonic sensor is below $15 \mathrm{~cm}$. The results of testing the value of the ultrasonic sensor distance found different conditions that occur. In a distance of $>15 \mathrm{~cm}$, the condition of the prototype cleaning robot for the road floor cleaning is obtained, while the distance $<15 \mathrm{~cm}$, the condition for the prototype of the street floor cleaning robot has stopped.
\end{abstract}

Keywords- Arduino Uno, Motor Dc, Motor Shield L298, Ultrasonic Sensor, Robot, Floor Cleaner.

\section{INTRODUCTION}

Cleanliness is the activity of creating or creating a clean, beautiful, beautiful, green and comfortable environment. Cleanliness, of course, is not only in one place, for example, cleanliness of the office, namely cleanliness of the place of work, cleanliness of the school, namely the cleanliness of the place to study or study, and so on was studied by goon [1].

Cleanliness is an inseparable part of human life and is an interconnected element in health science was studied by kaur [2]. Cleanliness is a prerequisite for the realization of health, a clean environment will provide great benefits to humans and on the other hand a dirty environment will give people big problems was studied by sahu [3]. The job of cleaning the floor of a room may seem very simple, but actually a lot of time and energy is used was studied by liu [4]. Human limitations and lifestyles that do not care about the cleanliness of the surrounding environment, as well as technological limitations that may be a factor for someone to not pay attention to the cleanliness of their environment was studied by kukde [5].

Therefore, researchers are innovating to make simple tools that can help the community or cleaning workers to clean floors was studied by muthugala [6]. Researchers want to develop technology while maintaining cleanliness and keeping abreast of technologies that are currently developing was studied by juang [7]. Therefore, the researcher wants to make a technology design that can clean a room by cleaning the floor automatically was studied by al-busaidi [8]. By using a familiar component, namely the Arduino Uno as the microcontroller, the DC (direct current) motor as the driving force, this is because the electronically controlled equipment provides more convenience in its use was studied by Araujo [9]. Then an automatic floor cleaning robot was designed using an ultrasonic sensor was studied by gargava [10]. This device can be an alternative to helping the public or cleaning workers to clean floors which is done automatically was studied by patil [11].

\section{METHODS}

Researchers use the prototype method because it aims to communicate more closely with program customers was studied by Irawan [12]. The design focuses on "listen to customer" so in the process of modeling between development and customers, they communicate more (feedback) in the design was studied by muthiah [13]. In essence, the developer is more emphasized to communicate more to meet the needs of the system customer was studied by muhardi [14]. In the first stage "Listen to Customer", which carries out the communication process with development which is directly implemented with the wishes of the customer with the "Build / Revise Mock-Up" stage, namely making semi-finished modeling and proceeding to the "Customer Test Drives Mock-Up" stage was studied by takeshita [15]. is an activity test program to the customer what is expected or if there is something that you want to add from the system program that is designed if there is a need that is less then proceed to the original stage "Listen to Customer" continues to loop until the program system designed is sufficient satisfy the customer in terms of system requirements was studied by Irawan [16].

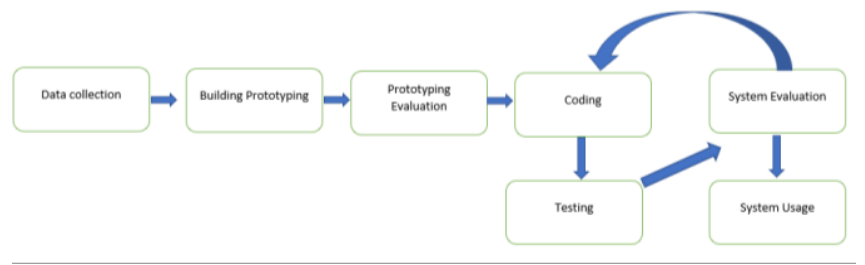

Fig. 1. Prototype Model

The following are the stages of development. The Sequential Prototype Model according to Darmawan [17]:

1. Data Collection

Requirements Collection is the stage where the client and developer jointly define the software and identify needs 
and systems that are created in consultation with the community was studies by kim [18].

\section{Building Prototype}

At this stage of building prototyping, a temporary design will be made that focuses on serving the customer was studied by seemuang [19].

3. Prototyping Evaluation

In the Prototyping Evaluation Phase, the results of the software design will be realized to the public, whether the prototyping built is in accordance with the wishes and needs of the customer or not was studied by candelas [20]. If it does not match, the prototyping will be revised by repeating the previous steps. But if it is appropriate, then the next step will be carried out was studied by young [21].

\section{Coding}

In the System Coding Stage, the agreed prototyping is translated into the appropriate programming language was studied by jeon [22].

\section{Testing}

In the System Testing Stage, after a software is ready to use, the software must be tested before use. This aims to minimize the software errors. Testing is done with Black Box, White box, Architectural testing, Base path and others was studied by Irawan [23].

6. System Evaluation

In the System Evaluation Stage, consumers evaluate the system that has been made as desired. If not, then the developer will repeat steps 4 and 5. But if so, then step 7 will do was studied by vanhuy [24].

7. System Usage

In the stage of using the system, the software that has been tested is installed and can be accessed and accepted by the client / customer was studied by ramani [25].

\section{IMPLEMENTATION RESULT}

Hardware design is a design or series of tools used to build an automatic floor cleaning robot prototype using Arduino and ultrasonic sensors.

1. Arduino Microcontroller Circuit with Ultrasonic and Servo Sensors. This Ultrasonic Sensor functions as a distance detector which is connected to the Arduino Microcontroller so that the distance can block the robot and the Servo functions as a motion controller with the Arduino Microcontroller to help move the ultrasonic sensor.

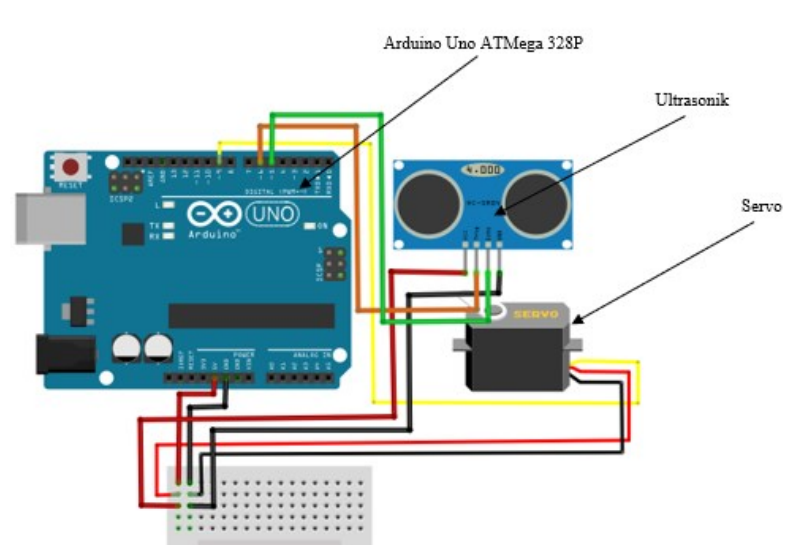

Fig.3. Arduino Microcontroller Circuit with Ultrasonic and Servo Sensors

2. Arduino Microcontroller Circuit with Motor Dc and Motor Shield L298. This Dc motor functions as a robot driver which is connected to the Arduino Microcontroller so that it can run the robot and mop automatically and the Motor Shield L298 functions as a motion regulator connected to the Arduino Microcontroller in order to regulate the motion of the $\mathrm{dc}$ motor was studied by was studied by wahyuni [26].

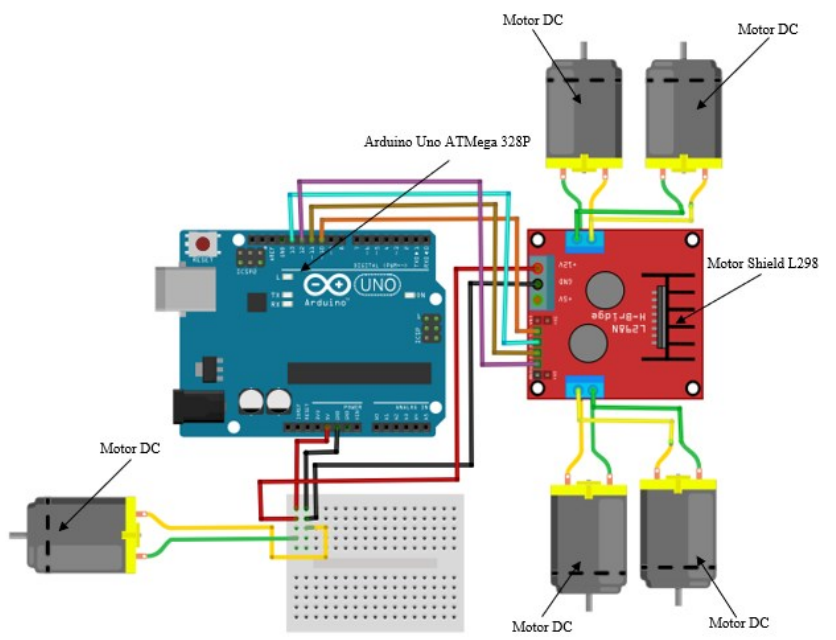

Fig. 3. Arduino Microcontroller Circuit with Motor Dc and Motor Shield L298

3. The whole set of hardware configurations.

The picture below is a series of prototype automatic floor cleaning robots using Arduino and ultrasonic sensors.

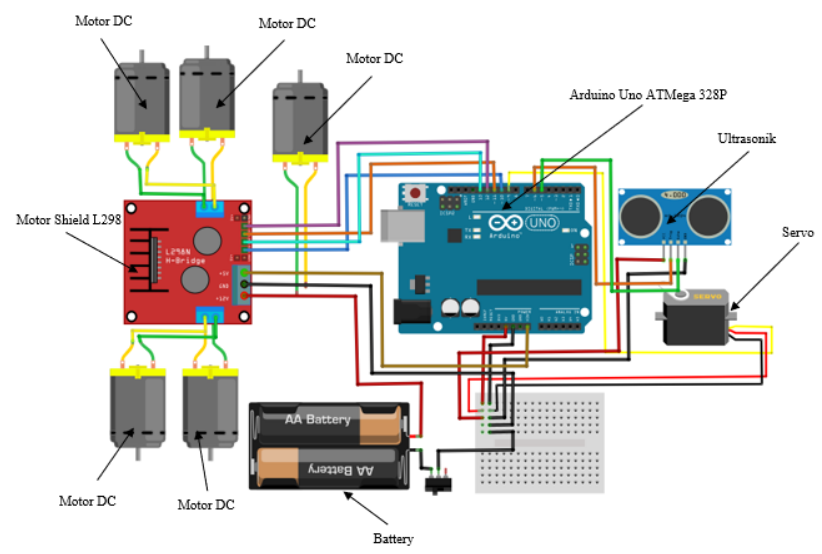

Fig. 4. The overall series of hardware configurations 
Implementation is one of the stages in system development, where this stage is the stage of placing a prototype of an automatic floor cleaning robot so that it is ready for operation and can be seen as an effort to realize the system that has been designed was studied by VPH [27].

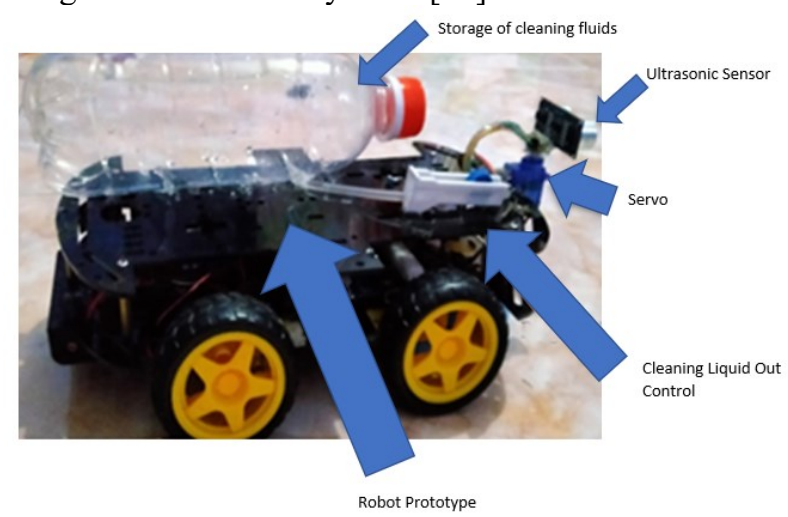

Fig. 5. The overall series of hardware configurations

\section{A. System Testing}

Testing the Arduino Uno system on an automatic floor cleaning robot prototype can be done in the following steps:

1. Connect the battery to the hardware assembly of the automatic floor cleaning robot prototype and press the on button.

2. After that, the automatic floor cleaning robot prototype will turn on like the supporting devices, namely Arduino Uno, Ultrasonic Sensor, Motor Shield L298, Servo, and Motor Dc.

3. After the automatic floor cleaning robot prototype is connected to its supporting devices, the ultrasonic sensor will detect the distance that is an obstacle.

4. When the automatic floor cleaning robot prototype detects the distance that is an obstacle, the robot automatically looks for a direction that is not a barrier to the floor cleaning robot was studied by lee [28].

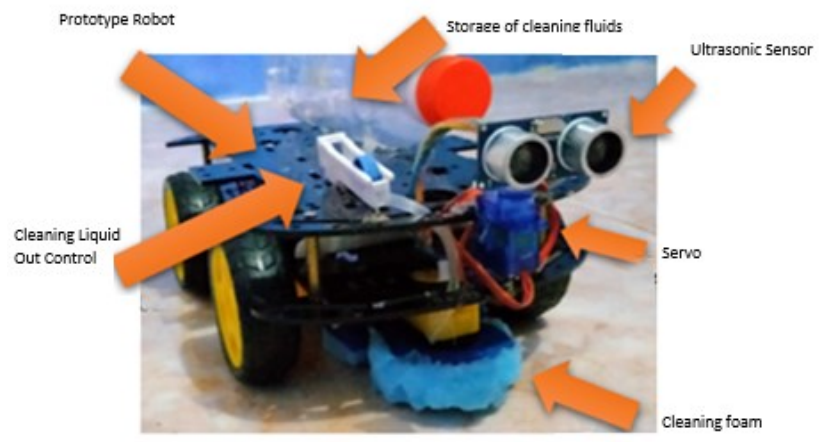

Fig. 6. Automatic Floor Cleaning Robot Prototype detects distance

\section{B. Ultrasonic Sensor Testing}

Testing by testing the distance on the ultrasonic sensor. The distance value on the sensor has been determined, that is, when the distance read by the ultrasonic sensor is below 15 $\mathrm{cm}$, the floor cleaning robot prototype will automatically stop and the robot prototype will look for a direction that does not obstruct it was studied by zhang [29].
Table 1. Ultrasonic Sensor Testing

\begin{tabular}{|c|c|c|c|}
\hline Distance & Barrier & Condition & Validation \\
\hline$>15 \mathrm{CM}$ & Nothing & $\begin{array}{c}\text { The prototype of a } \\
\text { street floor cleaning } \\
\text { robot }\end{array}$ & Success \\
\hline$<15 \mathrm{CM}$ & Front & $\begin{array}{c}\text { The floor cleaning } \\
\text { robot prototype stops } \\
\text { then turns left or right }\end{array}$ & Success \\
\hline$<15 \mathrm{CM}$ & Front and Left & $\begin{array}{c}\text { The floor cleaning } \\
\text { robot prototype stops } \\
\text { then turns right }\end{array}$ & Success \\
\hline$<15 \mathrm{CM}$ & Front, Left & $\begin{array}{c}\text { The floor cleaning } \\
\text { robot prototype } \\
\text { stopped then turned } \\
\text { backwards }\end{array}$ & Success \\
\hline
\end{tabular}

The results of testing the value of the ultrasonic sensor distance found different conditions that occur. In a distance of $>15 \mathrm{~cm}$, the condition of the prototype cleaning robot for the road floor cleaning is obtained, while the distance $<15$ $\mathrm{cm}$, the condition for the prototype of the street floor cleaning robot has stopped was studied by wahyuni [30]. From the results of this test, the prototype of the floor cleaning robot will automatically stop when there is a barrier, then turn according to the test that the researcher has made in the table above was studied by jeon [31].

\section{CONCLUSION}

Based on the results of the analysis, design and implementation that has been done. So, some conclusions can be drawn, namely the automatic floor cleaning robot prototype is quite effective in helping the community or cleaning workers to clean floors was studied by liang [32]. Build an automatic floor cleaning robot prototype using the Arduino Uno Microcontroller as a data processor and an ultrasonic sensor as a distance controller which when someone blocks it, the floor cleaning robot prototype will automatically run in the direction that no one is blocking it. Automatic floor cleaning robot prototype using ultrasonic sensors can more effectively detect the distance blocking it.

\section{REFERENCES}

[1] Goon, L. H., Isa, A. N. I. M., Choong, C. H., \& Othman, W. A. F. W. Development of Simple Automatic Floor Polisher Robot using Arduino. International Journal of Engineering Creativity \& Innovation, 1(1), 2019, 17-23.

[2] Kaur, M., \& Abrol, P. Design and development of floor cleaner robot (automatic and manual). International Journal of Computer Applications, 2014, 97(19).

[3] Sahu, N. K., Sharma, N. K., Khan, M. R., \& Gautam, D. K. Comparative Study on Floor Cleaner. Journal of Pure Applied and Industrial Physics, 2018, 8(12), 233-236.

[4] Liu, C. C., Kang, Y. P., \& Yu, S. N. Hardware and software integration for domestic stairs cleaning robot. In SICE Annual Conference 2011 (pp. 663-670). IEEE.

[5] Kukde, M., Nagpurkar, S., Dhakulkar, A., \& Amdare, A. Automatic \& manual vacuum cleaning robot. International Research Journal of Engineering and Technology (IRJET), 2018, 5(02), 2196-2198.

[6] Muthugala, M. V. J., Vengadesh, A., Wu, X., Elara, M. R., Iwase, M., Sun, L., \& Hao, J. Expressing attention requirement of a floor cleaning robot through interactive lights. Automation in Construction, 2020, 110,103015 .

[7] Juang, H. S., \& Lurrr, K. Y. Design and control of a two-wheel selfbalancing robot using the arduino microcontroller board. In 2013 10th 
IEEE International Conference on Control and Automation (ICCA) (pp. 634-639). IEEE.

[8] Al-Busaidi, A. M. Development of an educational environment for online control of a biped robot using MATLAB and Arduino. In 2012 9th France-Japan \& 7th Europe-Asia Congress on Mechatronics (MECATRONICS)/13th Int'l Workshop on Research and Education in Mechatronics (REM), 2012 (pp. 337-344). IEEE.

[9] Araújo, A., Portugal, D., Couceiro, M. S., \& Rocha, R. P. Integrating Arduino-based educational mobile robots in ROS. Journal of Intelligent \& Robotic Systems, 2015, 77(2), 281-298.

[10] Gargava, P., Sindwani, K., \& Soman, S. Controlling an arduino robot using Brain Computer Interface. In Proceedings of 3rd International Conference on Reliability, Infocom Technologies and Optimization (2014, pp. 1-5). IEEE.

[11] Patil, D. A., Upadhye, M. Y., Kazi, F. S., \& Singh, N. M. Multi robot communication and target tracking system with controller design and implementation of swarm robot using arduino. In 2015 International Conference on Industrial Instrumentation and Control (ICIC) (pp. 412-416). IEEE.

[12] Irawan, Y., Fernando, Y., \& Wahyuni, R. Detecting Heart Rate Using Pulse Sensor As Alternative Knowing Heart Condition. Journal of Applied Engineering and Technological Science (JAETS),2019, 1(1), pp 30-42.

[13] M. Muthiah, K. Nirmal and R. Sathiendran, "Low cost radio frequency controlled robot for environmental cleaning," 2015 International Conference on Circuits, Power and Computing Technologies [ICCPCT-2015], Nagercoil, 2015, pp. 1-5, doi: 10.1109/ICCPCT.2015.7159519.

[14] Muhardi, Muhardi, et al. "Design Of Web Based LMS (Learning Management System) in SMAN 1 Kampar Kiri Hilir." Journal of Applied Engineering and Technological Science (JAETS) 1.2 (2020): 70-76.

[15] T. Takeshita, T. Tomizawa and A. Ohya, "A House Cleaning Robot System -Path indication and Position estimation using ceiling camera," 2006 SICE-ICASE International Joint Conference, Busan, 2006, pp. 2653-2656, doi: 10.1109/SICE.2006.315049.

[16] Irawan, Yuda. "Implementation Of Data Mining For Determining Majors Using K-Means Algorithm In Students Of SMA Negeri 1 Pangkalan Kerinci." Journal of Applied Engineering and Technological Science (JAETS) 1.1 (2019): 17-29.

[17] Darmawan. Software Engineering (Rekayasa Perangkat Lunak) (Erlangga; Erlangga, ed.). 2013, Jakarta: Erlangga.

[18] H. Kim, J. Yang and D. Kwon, "Experience based domestic environment and user adaptive cleaning algorithm of a robot cleaner," 2014 11th International Conference on Ubiquitous Robots and Ambient Intelligence (URAI), Kuala Lumpur, 2014, pp. 176-178, doi: 10.1109/URAI.2014.7057525.

[19] N. Seemuang, "A cleaning robot for greenhouse roofs," 2017 2nd International Conference on Control and Robotics Engineering (ICCRE), Bangkok, 2017, pp. 49-52, doi: 10.1109/ICCRE.2017.7935040.

[20] Candelas, F. A., García, G. J., Puente, S., Pomares, J., Jara, C. A., Pérez, J., ... \& Torres, F. Experiences on using Arduino for laboratory experiments of Automatic Control and Robotics. IFACPapersOnLine, 48(29), 2015, 105-110.

[21] Young-Ho Choi, Jae-Youl Lee, Jong-Deuk Lee and Ka-Eun Lee, "SMART WINDORO V1.0: Smart window cleaning robot," 2012 9th International Conference on Ubiquitous Robots and Ambient Intelligence (URAI), Daejeon, 2012, pp. 116-119, doi: 10.1109/URAI.2012.6462948.

[22] S. Jeon, M. Jang, D. Lee, C. Lee and Y. Cho, "Strategy for cleaning large area with multiple robots," 2013 10th International Conference on Ubiquitous Robots and Ambient Intelligence (URAI), Jeju, 2013, pp. 652-654, doi: 10.1109/URAI.2013.6677414.

[23] Irawan, Yuda, Yunior Fernando, and Refni Wahyuni. "Detecting Heart Rate Using Pulse Sensor As Alternative Knowing Heart Condition." Journal of Applied Engineering and Technological Science (JAETS) 1.1 (2019): 30-42.

[24] VanHuy, T., Minh, D. T., Kien, N. P., \& Vu, T. A. Simple robotic hand in motion using arduino controlled servos. International Journal of Science and Research (IJSR), 2017, 6(3), 972-975.

[25] S. Ramani, A. Salunke, I. Ferrao and E. Noronha, "Automated Tile Polishing Robot," 2019 International Conference on Nascent Technologies in Engineering (ICNTE), Navi Mumbai, India, 2019, pp. 1-5, doi: 10.1109/ICNTE44896.2019.8946055.

[26] Wahyuni, Refni; IRAWAN, Yuda. Web-Based Employee Performance Assessment System in PT. Wifiku Indonesia. Journal of Applied Engineering and Technological Science (JAETS), 2020, 1.2: 60-69.

[27] V. P.H., L. V., M. K., R. P.S. and S. R., "Sweepy - The Smart Floor Cleaner," 2018 International Conference on Design Innovations for 3Cs Compute Communicate Control (ICDI3C), Bangalore, 2018, pp. 124-126, doi: 10.1109/ICDI3C.2018.00035.

[28] J. H. Lee, J. S. Choi, B. H. Lee and K. W. Lee, "Complete coverage path planning for cleaning task using multiple robots," 2009 IEEE International Conference on Systems, Man and Cybernetics, San Antonio, TX, 2009, pp. 3618-3622, doi: 10.1109/ICSMC.2009.5346856.

[29] G. Wu, L. Zhang, H. Zhang and B. Zhang, "Research on Design of Glass Wall Cleaning Robot," 2018 5th International Conference on Information Science and Control Engineering (ICISCE), Zhengzhou, 2018, pp. 932-935, doi: 10.1109/ICISCE.2018.00194.

[30] Wahyuni, Refni; Irawan, Yuda. Web-Based Heart Disease Diagnosis System With Forward Chaining Method (Case Study Of Ibnu Sina Islamic Hospital). Journal Of Applied Engineering And Technological Science (Jaets), 2019, 1.1: 43-50.

[31] S. Jeon, M. Jang, D. Lee, Y. Cho and J. Lee, "Multiple robots task allocation for cleaning a large public space," 2015 SAI Intelligent Systems Conference (IntelliSys), London, 2015, pp. 315-319, doi: 10.1109/IntelliSys.2015.7361161.

[32] Liang Yuming, Wen Ruchun, Zhang Zhenli and Zhu Junlin, "Dynamic coverage path planning and obstacle avoidance for cleaning robot based on behavior," 2011 International Conference on Electric Information and Control Engineering, Wuhan, 2011, pp. 4952-4956, doi: 10.1109/ICEICE.2011.5777555. 